First Draft

Comments Welcome

\title{
Hot Markets, Investor Sentiment, and IPO Pricing
}

\author{
Alexander P. Ljungqvist \\ NYU Stern School of Business \\ aljungqv@stern.nyu.edu \\ Vikram Nanda \\ University of Michigan Business School \\ vnanda@umich.edu \\ Rajdeep Singh \\ University of Minnesota \\ rajsingh@tc.umn.edu
}

September 18, 2001

We are grateful to Ross Levine, James Montier, and William Wilhelm for helpful feedback. The usual disclaimer applies. 


\title{
Hot Markets, Investor Sentiment, and IPO Pricing
}

\begin{abstract}
Our model of the initial public offering process links the three main empirical IPO 'anomalies' - underpricing, hot issue markets, and long-run underperformance - and traces them to a common source of inefficiency. We relate hot IPO markets (such as the 1999/2000 market for Internet IPOs) to the presence of a class of investors who are 'irrational' in the sense of having exuberant expectations regarding future performance. Underpricing and long-run underperformance emerge as underwriters attempt to maximize profits from the sale of equity, at the expense of these exuberant investors. Underpricing serves to compensate regular IPO investors for their role in restricting the supply of available shares and maintaining prices. The model is shown to be consistent with many aspects of the IPO process. It also generates a number of new empirical predictions.
\end{abstract}




\section{Introduction}

The literature has identified several anomalous aspects to the process by which firms go public. At the time of being brought to the market, initial public offerings (IPOs) appear to be substantially 'underpriced' and exhibit positive initial day returns on average. More disturbing to the notion of market efficiency, however, is the finding that the initial price run-up appears to be undone in subsequent months as IPO stocks underperform stocks of matched firms. ${ }^{1}$ Hence, over a longer horizon, IPOs can arguably be considered 'overpriced' at the start of trading. These patterns have been shown to vary over time, with both the initial price run-up and subsequent performance susceptible to the 'hot' and 'cold' periods of the market [Ritter $(1984,1991)]$.

What is one to make of these price patterns? The literature offers no consensus. Numerous articles model the initial underpricing - an empirical fact that was recognized and studied well before work on longer-term price patterns emerged. For the most part these formal models, based as they are on investor rationality in incomplete information settings, have shed little light on the long-run performance of IPOs. ${ }^{2}$ In contrast, work on long-run underperformance is primarily empirical and emphasizes the role of investor sentiment and bounded rationality in driving the price behavior of IPO stocks. The impact of investor sentiment is regarded as particularly acute in periods characterized by excessive investor optimism about particular types of IPO stocks ('hot markets'). Over time, investor exuberance fades, resulting in long-run underperformance. The patterns may persist despite the possibility of arbitrage by rational investors, on account of risk-aversion and the costs of implementing arbitrage [Shleifer and Vishny (1997)].

The behavioral story sketched above has some obvious appeal. But a legitimate question about its usefulness is whether it can also provide insights into other well-established patterns and institutional features of the IPO market, such as the strong bonds that ex-

\footnotetext{
${ }^{1}$ See Ritter (1991) and others. We assume the existence of IPO underperformance notwithstanding recent papers which have questioned its nature and significance [Brav, Geczy, and Gompers (2000), Eckbo, Masulis, and Norli (2000)].

${ }^{2}$ Among these are explanations based on the 'winner's curse' [Rock (1986)], signaling [Allen and Faulhaber (1989), Welch (1989)], cascades [Welch (1992)], and investor incentives to reveal information truthfully [Benveniste and Spindt (1989)].
} 
ist between top underwriters and regular institutional investors, allocation practices that discriminate against retail investors, underwriters' price support activities, penalty bids on syndicate members whose clients 'flip' the stock in the early after-market, lock-up provisions barring insiders from selling shares in the first 180 days, and so on.

More generally, if behavioral finance is to be more than ex-post rationalization, it needs to be capable of generating refutable empirical predictions. To highlight the issue, consider IPO underpricing. Should we expect this to be related to the presence of sentiment investors? In our view, it is difficult to obtain a prediction without additional structure on behavioral assumptions and the nature of the economic environment. After all, it seems plausible that the presence of sentiment investors could lead to higher offer prices and a lower level of underpricing as rational issuers take advantage of them. A behavioral argument in Loughran, Ritter, and Rydqvist (1994) is that issuers 'time' their IPOs to coincide with periods of excessive optimism. Without getting into the merits of this specific claim, it has the drawback of introducing yet another layer of behavioral assumptions: issuers are regarded as rational enough to choose a hot market in which to go public yet they go along with an obviously inefficient way of setting the offer price.

Our objective in this paper is to offer a simple model of the pricing and other features of the IPO process. We start with the premise that some investors may, on occasion, be 'irrationally exuberant' about the prospects of IPOs from a particular industry. We show this to be consistent with long-run IPO underperformance. ${ }^{3}$ More interestingly, the model suggests that it may be optimal for an underwriter to underprice the IPO as a way to pricediscriminate among rational and exuberant investors - thereby maximizing the benefit to the issuer. Due to uniform pricing rules, U.S. underwriters are prevented from charging different investors different prices. Our model shows how the cooperation of regular (institutional) investors can circumvent uniform pricing rules. Effectively, underwriters can delegate price discrimination by allocating greater quantities of stock to their regulars who, in turn, pick off exuberant investors along the demand curve in after-market trading. In return, the regulars'

\footnotetext{
${ }^{3}$ Brav and Gompers (1997) show that underperformance is concentrated amongst small, non-venture backed companies. These are the sorts of companies whose stock is more likely to be owned by individuals, who in turn may be more easily influenced by fads or lack of complete information.
} 
trading profits are at least partly capitalized into a higher offer price than would otherwise be the case. The extent to which issuers benefit depends on the relative bargaining power of regulars, though we leave the bargaining game unmodeled. There will still be underpricing, in part to compensate regulars for the risk of the hot market ending and having to off-load their excess inventory at a loss, and in part reflecting relative bargaining power.

Implicit in our modeling of the resulting institutional arrangements is the assumption that there are an insufficient number of sentiment investors to absorb the entire offering at the IPO. In this case, regular investors are expected to hold part of their IPO allocation as inventory, selling to newly-arriving sentiment investors if the hot market persists. If sentimental demand is sufficiently high at the time of the IPO, on the other hand, underwriters will sell directly to the exuberant investors and there will be no need to underprice.

For the inventory holding strategy to be implemented, it must be incentive compatible for the regular investors not to deviate by selling their entire allocation immediately after the offering, as this would depress prices. For incentive compatibility it may be necessary for the underwriter to punish "excessive" flipping by, say, excluding the investor from future IPO allocations. The manner in which the punishment strategy works is similar to notions that have been advanced in other work [Benveniste and Spindt (1989)].

Most of the work in behavioral finance focuses on asset pricing anomalies, such as the predictability of returns, the equity premium puzzle, and under- and over-reactions [for an exhaustive survey of the literature, see Hirshleifer (2001)]. Our model is an attempt to capture the equilibrium response of issuers, underwriters, and rational investors to the emergence of exuberant investors. It is thus related to a small empirical literature in which firms act strategically to take advantage of the market's mispricing or mis-perceptions. ${ }^{4} \mathrm{We}$ do not attempt to rationalize the existence or behavior of exuberant investors. Biases that might lead to such behavior have been studied by psychologists for some time and financial economists have recently introduced them into formal models of asset pricing. For example, a large literature shows that people believe their knowledge to be more accurate than it

\footnotetext{
${ }^{4}$ For example, see D'Mello and Shrof (2000) and Dittmar (2000) on firms using share repurchases strategically, and Korajczyk, Lucas and McDonald (1991) on firms timing seasoned equity offers strategically.
} 
really is [for a review, see Odean (1998)]. Overconfidence can persist if economic agents do not appropriately learn from outcomes, which may be due to another bias, 'self-attribution'. Experiments have shown that people tend to attribute favorable outcomes to their abilities and unfavorable ones to chance or other external factors beyond their control [see Daniel, Hirshleifer, and Subrahmanyam (1998) for a discussion of the psychology literature]. ${ }^{5}$

Our model generates a number of novel empirical predictions:

- As investor sentiment grows, IPO offer sizes increase. Lower-quality companies are taken public, resulting in a decrease in average issuer quality. Companies become more likely to raise money for non-investment purposes, such as paying down debt.

- At the beginning and end of a hot market, initial returns and long-run underperformance are both larger.

- Underwriters penalize investors who engage in excessive flipping. Importantly, they do so even in IPOs that do not receive price support. Such penalties are targeted primarily at retail and infrequent investors.

- Corporate insiders are released early from their lock-up provisions, if after-market demand from sentiment investors is unexpectedly high, once regular investors have unloaded their excess inventory, or if the hot market has come to an end.

The model also generates predictions that may resolve hitherto puzzling empirical findings:

- Ritter (1991) documents that underpricing and long-run performance are negatively related, while Krigman, Shaw, and Womack (1999) find a positive relation. Our model shows that the relation is not necessarily monotonic. In particular, we show that the relation is negative only if the probability of the hot market ending is small.

\footnotetext{
${ }^{5}$ Daniel et al. (1998) combine the two biases to show a favorable initial shock to private information causes the price to rise beyond the unbiased value. Accumulating evidence eventually forces investors to a more reasonable self perception. This leads to positive short-lag correlations and negative long-lag correlations. Our sentiment investors could possibly be going through similar cycles. In a related paper, Gervais and Odean (2001) analytically model the learning process under self-attribution bias.
} 
- Ritter and Loughran (2001) report evidence that the revision of the offer price relative to the filing range is predictable using public information and argue this contradicts Benveniste and Spindt's (1989) private information acquisition model. In our model, the 'partial adjustment' of the offer price is driven by the difference in opinion between rational and sentiment investors and not by private information. Thus, unlike Benveniste and Spindt (1989), our model can accommodate partial adjustment in response to public stock price movements.

- The empirical evidence on the relation between underwriter prestige and underpricing is mixed. Consistent with evidence from the 1990s, we predict that underpricing increases in underwriter prestige, but that this relation depends on the state of the IPO market.

Finally, the model is consistent with several well-established patterns and institutional features of the IPO market, including underwriters' preference for selling to regular (typically institutional) investors, the existence of lock-up provisions, the negative price impact of lock-up expiry, and the provision of price support.

\section{The Model}

The situation we model is one of a firm going public in a 'hot' IPO market. The firm's owner-managers wish to take their firm public in part to benefit from the favorable climate for IPOs. They may have been encouraged, for instance, by the market's enthusiastic reception of IPOs by other firms in their industry. The characteristics of the offering, such as the quantity of shares offered and, indirectly, the offer price, will be chosen to maximize the wealth of the firm's owner-managers. We denote the quantity and offer price of IPO shares by $Q$ and $P_{0}$, respectively.

The offering is assumed to take the standard form of a firm-commitment offering in which an underwriter (or underwriting syndicate) assumes responsibility for distributing shares to investors. The underwriter acquires the issuer's shares for resale at a fixed offer price. The offer price is finalized at the end of bookbuilding, just prior to the start of selling. 
The demand side of the market consists of two types of investors. The first type consists of small, unsophisticated investors who are infrequent participants in the stock market. Such investors are assumed to have a non-rational streak and to be prone to episodes of optimistic or pessimistic sentiment. In our set-up a hot IPO market, not surprisingly, corresponds to an optimistic period. As discussed later, sentiment or 's-type' investors only deviate from rationality in a specific and limited way, namely their excessive optimism about the prospects of firms going public. ${ }^{6}$

The second type of investor holds the appropriate, rational beliefs about the prospects for the IPO shares. It may be reasonable, for instance, to regard institutional investors as belonging to this category. All other market participants (issuers, underwriters) are taken to be rational and value-maximizing as well. There is no private or asymmetric information in the model, and the nature and characteristics of the market participants and their beliefs is common knowledge. Hence, the sentiment investors and the various rational investors know each others' beliefs, but still 'agree to disagree' on the valuation of the IPO shares. ${ }^{7}$ For simplicity, investors and other market participants are taken to be risk-neutral.

The model has four relevant dates: $t=0,1,2$ and $T$. At $t=0$, the period prior to the offering, the pricing and other features of the IPO are determined. Date $t=1$ is the initial day of trading in the IPO shares, while $t=2$ represents a subsequent trading date. $T$ is the terminal date by which the hot market is over and there is no more disagreement about firm value.

Let $V_{T}$ denote the payoff of the security at the terminal date $T$. We assume there are no distributions (e.g. dividends) and the discount rate is zero. At $t=1$, the 'fundamental' or long-term expected value of an IPO share - the value from the perspective of rational investors - is denoted by $V_{R}=E\left(V_{T}\right)$. Absent sentiment investors and additional infor-

\footnotetext{
${ }^{6}$ This mirrors Miller's (1977) divergence-of-opinion model. Sentiment investors are 'irrational' in the sense of sticking to their beliefs even though they know these do not coincide with the market consensus. Their beliefs might, for instance, be driven by a 'halo effect' [Nisbett and Wilson (1977)]. The halo effect causes an individual to extend a favorable evaluation of one characteristic to other characteristics. For example, a favorable evaluation of a firm's product might be extended to its expected future stock returns, or investors might extend positive news about a firm's accounting earnings to its stock returns [see Lakonishok, Shleifer and Vishny (1994), Shefrin and Statman (1995)].

${ }^{7}$ This is similar to the structure in Harris and Raviv (1993).
} 
mation, $V_{R}$ would be the market price of the IPO shares at $t=1$. As we will discuss, the presence of sentiment investors, with their more optimistic valuations, can affect the pattern of market prices of IPO shares. The question of interest to us is not so much the existence of irrationality per se, but rather the impact optimistic investors may have on pricing and trading patterns, and thus on the institutional arrangements that result.

The value sentiment investors place on IPO shares is not uniform. Specifically, we assume that these investors are budget constrained and that the aggregate demand curve for IPO shares by the $s$-type investors can be represented as:

$$
V_{s}=V_{R}+a-\lambda Q
$$

Here $Q$ is the total quantity of IPO shares that is held by $s$-type investors. Let us define $\bar{Q}=\frac{a}{\lambda}$. Hence for all $Q<\bar{Q} s$-type investors (if they are present) place a value higher than $V_{R}$ on the IPO shares. The $s$-type investors know the demand curve and the value put on the shares by rational investors.

We view the sentiment investors as infrequent traders, many of whom may not be active in the market at any particular time. Hence, we assume that sentiment demand builds over time as additional s-type investors arrive in the market - as long as the market stays hot. Thus equation (1) represents longer-term demand: while part of the demand is realized at $t=1$, there may be an additional inflow of optimistic investors if the hot market continues. ${ }^{8}$ We also assume that there is an exogenous probability $\gamma$ that the hot market comes to a crashing end at $t=2$. This captures the notion that by this time, there may be incontrovertible evidence of the IPO shares being overpriced. ${ }^{9}$ In this situation, the optimistic investors adjust their valuation of IPO shares to $V_{R}$ (or, alternatively, turn pessimistic and exit from the IPO market altogether). Except in their excessive optimism (and refusal to update in the absence of incontrovertible evidence), s-type investors act

\footnotetext{
${ }^{8}$ The fact that not all sentiment investors are present in the market at $t=1$ may be the result of the time required for information to disseminate among the less informed investors; for enthusiasm about the new IPO to build while the market stays hot; or the additional time needed for some sentiment investors to raise resources and bid for IPO shares.

${ }^{9}$ To avoid problems with Bayesian updating from a zero probability prior, it is easiest to assume that sentiment investors do have a prior non-zero, but infinitesimally small, probability of such a revision of their valuation. This does not affect any of the discussion and we will ignore this infinitesimal probability in the expressions.
} 
rationally given their optimistic beliefs. This includes the fact that they properly anticipate the prices of the security in the short run. Therefore, they would never be willing to pay a price at $t=1$ that is greater than the expected price conditional on their beliefs at $t=2$. Note here that we are maintaining the assumption that no short positions on the IPO stock are possible (or that they are simply too expensive to execute). ${ }^{10}$

Hence, so long as the hot market persists, the demand curve in equation (1) consists of the aggregation of optimistic investors that arrive at $t=1$ and those that arrive at $t=2$. Let $\bar{Q}_{1}<\bar{Q}$ denote the total 'optimistic' demand present at $t=1$.

The beliefs of rational and sentiment investors can be characterized as follows:

- At $t=1$, rational investors believe the long-run expected value to be $V_{R}$. They also know that the hot market will end at $t=2$ with probability $\gamma$.

- The optimistic investors, however, dismiss the possibility of the hot market coming to an end, ${ }^{11}$ since they consider their own beliefs to correct.

Given the beliefs specified above, the price of IPO shares at $t=2$ and, thereby, the offer and trading prices of IPO shares at $t=0$ and 1 can be determined. If the hot market comes to an end, the share price at $t=2$ will be set by the expectations of the rational investors such that $P_{2}=V_{R}$. If the hot market persists, the price will be given by equation (1). We assume here that the quantity of shares sold is such that $Q<\bar{Q}$. This, as we show later, is consistent with an optimal choice for $Q$. For a given quantity of shares issued at

\footnotetext{
${ }^{10}$ Lamont and Thaler (2000) argue that the apparent mispricing of recent tech stock carve-outs is due to the difficulty of finding shares to borrow in order to sell short. Houge, Loughran, Suchanek, and Yan (2000) discuss some of the reasons why this may be. First, brokers can only allow clients to short-sell if delivery of the borrowed shares can be guaranteed, which effectively rules out short sales in the first few days as share allocations are not distributed immediately. Second, short sellers face difficulty borrowing stock as regulations and market practices restrict the potential supply. Stock could in principle be borrowed from corporate insiders, syndicate banks, or investors who hold shares in the aftermarket. However, insiders in most IPOs are 'locked-up' for some period of time following the IPO, usually 180 days, which prevents them from selling or lending their shares. Banks in the IPO syndicate are prohibited by the SEC from lending shares in the first 30 days of trading. And most IPOs involve such a small part of the equity that the 'free float' in public hands tends to be very small. Geczy, Musto, and Reed (2001) show that borrowing IPO stock in the early after-market is extremely expensive in general, the more so, the higher was the initial day return. Over the first three days of trading, virtually no IPO in their sample is loaned.

${ }^{11}$ See footnote 9.
} 
$t=0, Q$, the valuations by the rational and $s$-type investors are determined by their beliefs as follows:

- Rational investors: $E^{R}\left(P_{2}\right)=\gamma V_{R}+(1-\gamma) E^{s}\left(P_{2}\right)$

- Sentiment investors: $E^{s}\left(P_{2}\right)=V_{R}+a-\lambda Q$

The expected values above represent the prices that $s$-type and rational investors should be willing to pay at $t=1$, given their beliefs regarding $P_{2}$. Note that the rational investors' valuation $E^{R}\left(P_{2}\right)$ is greater than their long-run valuation $V_{R}$, since they expect to be able to trade out of the security at $t=2$.

To summarize, the setting is one of a hot market, i.e. a market environment with optimistic $s$-type investors present at $t=1$. Not all potential investors are present at $t=1$ and, if the hot market persists, more are expected to show up at $t=2$. Rational investors expect the terminal value of the IPO shares to be $V_{R}$. Unlike the optimists, they recognize that the hot market may come to an early end at $t=2$, with probability $\gamma>0$. In the longer run, by the terminal date $T$, the hot market will end with certainty. All investors, rational or otherwise, act in a manner consistent with their beliefs.

\section{$3 \quad$ Selling IPO Shares}

We consider the optimal procedure for selling IPO shares by, say, an underwriter retained for the purpose. For now, we maintain the assumption that the offer quantity $Q$ is given exogenously. In our discussion we will allow underwriters to sell IPO shares at both $t=1$ and $t=2$, instead of necessarily selling in a single shot at $t=1$. As we will see, such discretion will have no impact if all the demand from $s$-type investors is present at $t=1$ or if the demand by $s$-type investors at $t=1$ is large enough to absorb the full offering.

Let $q_{1}$ be the quantity of IPO shares sold at $t=1$, while $q_{2}$ is sold at $t=2$. The expected proceeds, $\Psi$, to the issuer are:

$$
\Psi=q_{1} P_{1}+q_{2}\left(E^{s}\left(P_{2}\right)(1-\gamma)+V_{R} \gamma\right)
$$


Given their beliefs, $s$-type investors expect the price at $t=2$ to be $E^{s}\left(P_{2}\right)=V_{R}+a-$ $\lambda\left(q_{1}+q_{2}\right)$. Hence, so long as the $s$-type investors hold all the IPO shares issued at $t=1$, the marginal investor is an $s$-type investor and the price at $t=1$ will be $E^{s}\left(P_{2}\right)$. However, if $q_{1}>\bar{Q}_{1}$, the marginal investor is a rational investor and the price at $t=1$ will be $E^{R}\left(P_{2}\right)$. Thus we have:

$$
P_{1}=\left\{\begin{array}{ll}
V_{R}+a-\lambda\left(q_{1}+q_{2}\right) & \text { if } q_{1} \leq \bar{Q}_{1} \\
\gamma V_{R}+(1-\gamma)\left(V_{R}+a-\lambda\left(q_{1}+q_{2}\right)\right) & \text { if } q_{1}>\bar{Q}_{1}
\end{array} .\right.
$$

We will assume that the firm's managers act in a manner consistent with maximizing the wealth of the firm's current owners. ${ }^{12}$ The optimal $\left(q_{1}^{*}, q_{2}^{*}\right)$ can, therefore, be regarded as the solution to the following constrained optimization problem that the firm solves:

$$
\begin{aligned}
\max _{q_{1}, q_{2}} & \Pi \equiv \Psi-V_{R} Q=q_{1} P_{1}+q_{2}\left(E^{s}\left(P_{2}\right)(1-\gamma)+V_{R} \gamma\right), \\
\text { s.t. } & q_{1}+q_{2}=Q
\end{aligned}
$$

The next proposition provides, for a given $Q$, the optimal allocation between $q_{1}$ and $q_{2}$.

Proposition 1 For a given quantity of shares to be issued, $Q$, the optimal choice of $q_{1}^{*}$ and $q_{2}^{*}$ is such that

$$
\left(q_{1}^{*}, q_{2}^{*}\right)= \begin{cases}(Q, 0) & \text { if } Q \leq \bar{Q}_{1} \\ \left(\bar{Q}_{1}, Q-\bar{Q}_{1}\right) & \text { if } Q>\bar{Q}_{1}\end{cases}
$$

Proof. See the appendix.

The above proposition shows that the issuer may be able to do better by staggering the sale of equity over two time periods instead of one. By restricting the initial supply of shares, the issuer ensures that the marginal investor at $t=1$ is from the sentimental group. If the total quantity $Q$ to be sold is less than the demand by sentiment investors at $t=1$, then the issuer optimally chooses to set $q_{2}^{*}$ equal to zero. The intuition is straightforward. In our set-up there is no price advantage from delaying the sale of equity if it can be sold to sentiment investors at $t=1$. By delaying the sale of equity, the issuer is exposed to the risk of the market crashing at $t=2$. Hence, the issuer is strictly better-off by selling to the sentiment investors at $t=1$ and thus taking advantage of their mistaken belief that the hot market will persist at $t=2$.

\footnotetext{
${ }^{12}$ This is similar to assumptions made in, for instance, Myers and Majluf (1984).
} 
While the discussion above indicates that it may be optimal to sell an offering in stages, issuers and their underwriters do not usually conduct firm commitment offerings in a piecemeal fashion. We will, however, show that there may exist institutional arrangements that, in effect, achieve the same results. Some possible reasons why underwriters do not sell in stages are suggested below. These reasons should be regarded as speculative and outside the model. ${ }^{13}$

- To implement sales in a staged manner would require underwriters to finance inventories and so to bear (undiversified) price risk.

- In a hot market in particular, underwriters would have to finance large quantities of inventory, raising concerns about moral hazard and asymmetric information among their own shareholders and lenders.

- The model assumes that the underwriter adjusts the selling price at $t=2$, depending on whether the hot market persists or not. Allowing the underwriter to deviate from uniform pricing of the offering may, in practice, create its own problems, leading to concerns about price manipulation/insider dealing by underwriters.

We will, therefore, consider the role of alternative arrangements that rely on longer-term relationships with institutional investors. As we will argue, these arrangements can achieve the same ends as a staged sale.

\section{Inventory Holding by Institutional Investors}

The alternative arrangement we consider is one in which institutional (or other regular) investors purchase IPO shares at the offer price $P_{0}$. They resell some shares at $t=1$ and the rest at $t=2$, when the full demand by $s$-type investors is established (so long as the hot market persists).

\footnotetext{
${ }^{13}$ One could argue that shelf offerings and best-effort offerings have certain of these features. However, firm commitment offerings may have some advantages in terms of reducing uncertainty about the proceeds raised and the success of the offering, while, as we argue, giving up all the benefits from having flexibility to stage the sale.
} 
We conduct the analysis assuming that regular investors are willing to follow the optimal inventory holding strategy derived in Proposition 1, where the aggregate quantities sold in the secondary market at $t=1$ and $t=2$ are given by $q_{1}^{*}$ and $q_{2}^{*}$ respectively. To sustain this strategy in equilibrium, it must be rational for the regular investors not to deviate by selling their entire allocation at $t=1$. At $t=1$ shares could be sold at a price $P_{1}$ that is greater than the expected price at $t=2$, given their belief that $P_{1}=E^{s}\left(P_{2}\right)>E^{R}\left(P_{2}\right)$. Thus, the underwriter has to provide incentives for the regular investors not to flip all their stock 'too early'. These incentives can take the form of explicit punishment strategies, such as a credible policy of denying allocations of future IPO shares to investors who engage in excessive flipping. In the context of our model this makes perfect sense, since flipping beyond a certain amount (the regular investor's share of $q_{1}^{*}$ in the model) indicates 'cheating' on a strategy of holding part of the allocated shares till $t=2$. For now, we assume there exist sufficient threats of penalties that make it incentive compatible for regular investors to follow the optimal inventory holding strategy. We analyze, in the next section, the situation where the possible punishment strategies are limited and thus are insufficient to sustain the optimal $q_{1}^{*}$ and $q_{2}^{*}$.

From Proposition 1, holding inventory is only beneficial when the quantity to be sold is such that $Q>\bar{Q}_{1}$. In equilibrium, regular investors will invest in IPOs only if they do not expect to lose from following the inventory holding strategy. If an IPO share is bought at an offer price $P_{0}$, the participation constraint of the regular investors can be stated as:

$$
-Q P_{0}+q_{1}^{*} P_{1}+q_{2}^{*}\left[(1-\gamma) E^{s}\left(P_{2}\right)+\gamma V_{R}\right] \geq 0
$$

where $q_{1}^{*}$ and $q_{2}^{*}$ are given by (3). In the above equation, the first term on the LHS is the cost of purchasing all the shares in the IPO, assuming that regular investors receive the entire offering. The second and third terms on the LHS represent the cash flows received from selling at $t=1$ and $t=2$. The bracketed part of the third term is the price at which regular investors expect to be able to sell IPO shares at $t=2$.

Assuming the issuer does not need to raise a particular level of financing, his objective is simply to maximize his 'profit' from selling IPO shares. That is, his objective is to 
maximize the excess value, denoted by $\Pi$, of the proceeds over his own valuation, subject to the participation constraint defined in (4). Thus, the issuer solves

$$
\begin{aligned}
& \max _{P_{0}, Q} \Pi \equiv Q\left(P_{0}-V_{R}\right) \\
& \text { s.t. } \quad-Q P_{0}+q_{1}^{*} P_{1}+q_{2}^{*}\left[(1-\gamma) E^{s}\left(P_{2}\right)+\gamma V_{R}\right] \geq 0 .
\end{aligned}
$$

Lemma 1 The participation constraint will always be binding.

Proof. Suppose not. That is, the optimal $P_{0}$ and $Q$ are such that the constraint has slack. Then the issuer can increase $P_{0}$ and so increase his profits, which contradicts the optimality of $P_{0}$ and $Q$.

We can use the above lemma and simplify the firm's objective function to obtain:

$$
\max _{Q} \Pi \equiv\left[q_{1}^{*} P_{1}+q_{2}^{*} E^{s}\left(P_{2}\right)(1-\gamma)+q_{2}^{*} V_{R} \gamma\right]-Q V_{R}
$$

where $q_{1}^{*}$ and $q_{2}^{*}$ are given by (3). The first bracketed term on the RHS is the maximum amount that regular investors are willing to pay for the IPO shares, from the participation constraint in (4).

From Proposition 1 , we know $q_{1}^{*} \leq \bar{Q}_{1}$. Thus, $P_{1}$ is determined by $s$-type investors, on the basis of their expectation regarding $P_{2}$. Using $P_{1}=E^{s}\left(P_{2}\right)=V_{R}+a-\lambda Q$ in the above expression and simplifying, the issuer's objective function can be written as

$$
\max _{Q} \Pi \equiv\left(q_{1}^{*}(Q)+(1-\gamma) q_{2}^{*}(Q)\right)\left(a-\lambda\left(q_{1}^{*}(Q)+q_{2}^{*}(Q)\right)\right)
$$

In the above expression, we have explicitly recognized the dependence of $q_{1}^{*}$ and $q_{2}^{*}$ on $Q$.

Proposition 2 With cooperative regular investors the issuer's optimal choice of quantity $Q^{*}$ to be issued is given by

$$
Q^{*}=\left\{\begin{array}{ll}
\frac{a}{2 \lambda}-\frac{\bar{Q}_{1} \gamma}{2(1-\gamma)} & \text { if } \bar{Q}_{1}<\frac{a(1-\gamma)}{\lambda(2-\gamma)} \\
\frac{a}{2 \lambda} & \text { o.w. }
\end{array} .\right.
$$

The resulting choices of $q_{1}^{*}$ and $q_{2}^{*}$ are such that:

$$
\left(q_{1}^{*}, q_{2}^{*}\right)=\left\{\begin{array}{ll}
\left(\bar{Q}_{1}, \frac{a}{2 \lambda}-\bar{Q}_{1}\left(1+\frac{\gamma}{2(1-\gamma)}\right)\right) & \text { if } \bar{Q}_{1}<\frac{a(1-\gamma)}{\lambda(2-\gamma)} \\
\left(\frac{a}{2 \lambda}, 0\right) & \text { o.w. }
\end{array} .\right.
$$


Proof. We obtain the above expressions from first-order conditions obtained by taking the derivative of the firm's objective function w.r.t. $q_{2}$. It can be shown that there is a unique maximum because the SOC w.r.t. $q_{2}$ is negative.

Intuitively, the issuer needs regulars to hold inventory if $\bar{Q}_{1}$ is small enough (relative to total demand by sentiment investors), i.e. less than $\frac{a(1-\gamma)}{\lambda(2-\gamma)}$. So long as the hot market persists, regular investors who hold inventory sell it to newly-arrived sentiment investors at $t=2$. If the hot market disappears, they are left with shares priced at $V_{R}$. For regular investors to accept this negative-valued gamble, the initial offer price needs to be set at a discount relative to the price at which the shares are expected trade initially so that $P_{0}<E^{s}\left(P_{2}\right)=P_{1}$. In our model, the price of shares will eventually drift to $V_{R}$, where $V_{R}<P_{0}$ from the binding participation constraint of the regular investors. Thus, with regulars holding inventory that they dispose off over time, both an initial price run-up (underpricing) and long-run underperformance will be observed. These patterns can be viewed as arrangements that have, in effect, evolved as a means to maximize the value extraction from $s$-type investors.

Note that if $\bar{Q}_{1}$ is large (relative to sentiment investor demand), there are no benefits from having regular investors hold inventory and the offering being substantially underpriced. However, there will still be long-run underperformance, on account of the $s$-type investors, but without the accompanying underpricing. Hence, we do not expect a monotonic relation between underpricing and long-run underperformance. The next proposition summarizes the above discussion.

Proposition 3 With cooperative regular investors,

1. if $\bar{Q}_{1}$ is small enough such that $q_{2}^{*}>0$, then the IPO shares will exhibit an initial price run-up, i.e. $P_{0}<P_{1}$;

2. if $\bar{Q}_{1}$ is large then the shares will not exhibit an initial price run-up;

3. $\forall \bar{Q}_{1}$ the shares will exhibit long-run underperformance, i.e. $V_{R}<P_{1}$; and 
4. the initial price run-up and long-run underperformance will be related as follows:

$$
P_{1}-V_{R}=\frac{Q}{\gamma q_{2}}\left(P_{1}-P_{0}\right)
$$

Proof. From equation (4), the highest price $P_{0}$ regular investors are willing to pay is:

$$
P_{0}=P_{1} \frac{q_{1}}{Q}+\frac{q_{2}}{Q}\left(P_{1}(1-\gamma)+V_{R} \gamma\right)
$$

Substituting this in $P_{1}-P_{0}$, we obtain

$$
\begin{aligned}
P_{1}-P_{0} & =P_{1}-\left[P_{1} \frac{q_{1}}{Q}+\frac{q_{2}}{Q}\left(P_{1}(1-\gamma)+V_{R} \gamma\right)\right] \\
& =P_{1}\left[1-\frac{q_{1}}{Q}-\frac{q_{2}}{Q}(1-\gamma)\right]-V_{R} \gamma \frac{q_{2}}{Q} \\
& =\frac{\gamma q_{2}}{Q}\left(P_{1}-V_{R}\right)
\end{aligned}
$$

Now, $P_{1}=E^{s}\left(P_{2}\right)>V_{R}$. Thus, $\left(P_{1}-V_{R}\right)>0$. Therefore $\left(P_{1}-P_{0}\right)>0$ if and only if $q_{2}>0$ (or if and only if $\bar{Q}_{1}$ is small enough).

In the above discussion, the existence of sentiment investors is shown to be a necessary but not sufficient condition for the initial price run-up. Underpricing compensates regular investors for the potential costs of holding inventory. As shown in Proposition 3, if demand at $t=1$ is high enough, the issuer will choose not to take advantage of the possibility of more sentiment investors arriving at $t=2$ and, consequently, the initial price run-up will not exist.

On the other hand, long-run underperformance always exists in our set-up. Underperformance results from the overly optimistic valuation of sentiment investors and represents market inefficiency - sustained by the difficulty and cost of establishing short positions in the stock. The assumption of inefficiency is a building block in our model. The question is what such an assumption buys us in terms of explaining the empirical evidence on IPOs. A significant benefit of our approach is that it shows how the simultaneous existence of long-run underperformance and an initial price run-up can arise from the same source of inefficiency. As in any theoretical exercise, the test of our model lies not in the validity of its building blocks but in its ability to explain existing evidence and generate new empirical predictions. Hence, we turn to studying the properties of the initial price run-up and 
underperformance. Later we will discuss empirical evidence, where it exists, in relation to the model's predictions.

In the next proposition we study the patterns predicted by our model for the initial price run-up and long-run underperformance. We focus on two parameters of interest: the intercept of the sentiment investors' demand function $(a)$ and the probability of the hot market coming to an end $(\gamma)$. In the context of the model, both parameters are exogenous and affect the nature of the hot market. These parameters allow us to examine the effect of changes in the extent of participation by sentiment investors and of the hot market likely coming to an end.

Proposition 4 With cooperative regular investors:

1. the initial price run-up, long-run underperformance, the ratio of the initial price runup to underperformance, and the number of shares issued are all increasing in the sentiment (a) of the market;

2. long-run underperformance is increasing, and the number of shares issued is decreasing, in $\gamma ;$ and

3. the initial price run-up and the ratio of the initial price run-up to underperformance are increasing in $\gamma$ for low $\gamma$.

Proof. See the appendix.

An increase in the intercept of the demand function, $a$, can be interpreted as an increase in the optimism of the sentiment investors. As one might expect, issuers in our model respond to the higher demand by increasing the size of the offering. The prediction on the initial price run-up, however, is not obvious. It may seem anomalous that a more bullish market does not translate into a smaller initial price run-up: why don't issuers take advantage of the bullishness of the market and increase the offer price, resulting in a smaller initial price run-up? The reason why the initial price run-up increases with market sentiment is that the run-up is a way of compensating regular investors for taking on the 
risk of the hot market crashing at $t=2$. As the size of the offering is increased, the fraction of the offering carried over to $t=2$ also increases. As it turns out, regular investors need to be compensated more (on a per share basis) for taking on the risk of carrying this inventory.

An increase in $\gamma$, the probability of market sentiment turning sour, reduces the expected gain from holding inventory and selling shares at $t=2$. As a consequence, the issuer is better off reducing the quantity of shares issued. However, a reduction in the quantity issued increases the price at $t=1$, thus worsening long-run underperformance. An increase in $\gamma$ has two contrary effects on the initial price run-up. First, it increases the compensation required by regular investors due to the direct effect of an increase in the probability of a crash. Second, the indirect effect of a reduction in the quantity issued is to reduce the inventory regulars hold. Proposition 4 shows that the first effect dominates for low $\gamma$ as the percentage change in $q_{2}^{*}$ for low $\gamma$ is small. For high enough $\gamma, q_{2}^{*}$ goes to zero and so the initial price run-up disappears. For intermediate levels of $\gamma$, the change in the initial price run-up is ambiguous. Similar characteristics are inherited by the ratio of long-run underperformance to the initial price run-up. However, the relation between this ratio and the inventory as a fraction of the offering carried by the regular investors, described in the next corollary, is unambiguous.

Corollary to Proposition 3 The ratio of the initial price run-up to long-run underperformance $\left(\frac{P_{1}-P_{0}}{P_{1}-V_{R}}\right)$ and $\frac{q_{2}}{Q}$ are positively correlated.

In our discussion we assumed that regular investors have an incentive to cooperate with underwriters, delaying the sale of part of their IPO allocations. It may be more reasonable to assume, however, that an underwriter can obtain only a limited amount of cooperation from the investors. The effect of such a participation constraint on the pricing and other features of the offering are discussed next. 


\section{$5 \quad$ Limited Ability to obtain Cooperation from Institutional Investors}

Regular investors may only be willing to extend limited cooperation in holding inventory. The reason, as we have seen, is that regulars face a negative expected return from inventory at $t=1$. Hence, an underwriter's ability to induce cooperative behavior is determined by the extent to which he can offer inducements or threaten punishment. A likely form of punishment, as mentioned earlier, is the threat of exclusion of regular investors from future IPOs or other desirable deals. If the near-term outlook for the IPO market is bleak, or if the underwriter's market share is small, exclusion from future IPOs will provide only limited incentives for inventory holding.

We model the limits on potential punishment by assuming that regular investors' future benefit from maintaining a 'good' relationship with the underwriter is $R$ per share. On the margin, regulars can choose to sell a share at price $P_{1}$ at $t=1$, or sell at $t=2$ and expect to get $E^{R}\left(P_{2}\right)$, where

$$
E^{R}\left(P_{2}\right)=\gamma V_{R}+(1-\gamma) E^{s}\left(P_{2}\right)
$$

The potential loss from future exclusion from the IPO process, $R$, must be large enough to deter 'cheating'. ${ }^{14}$ Therefore, we need:

$$
\begin{aligned}
\quad & \geq q_{2}\left(P_{1}-E^{R}\left(P_{2}\right)\right) \\
\text { or } & R \geq q_{2}\left(P_{1}-\gamma V_{R}-(1-\gamma) E^{s}\left(P_{2}\right)\right)
\end{aligned}
$$

In equilibrium, if regular investors do hold on to their inventory, $P_{1}=E^{s}\left(P_{2}\right)=V_{R}+a-$ $\lambda\left(q_{1}+q_{2}\right)$. Substituting this in (5) the constraint reduces to

$$
R \geq \gamma q_{2}\left(a-\lambda\left(q_{1}+q_{2}\right)\right)
$$

The analysis presented in the earlier section corresponds, therefore, to the case where the above constraint has slack. We now consider the situation in which the constraint is binding, i.e. in which (6) is violated at the optimal $q_{1}^{*}$ and $q_{2}^{*}$. The next proposition shows that the

\footnotetext{
${ }^{14}$ This can be viewed as a situation in which the shares are sold to sentiment investors in a sequential manner. Hence, an investor who can sell his shares early benefits from selling his allocation at the higher price $P_{1}$.
} 
constraint is more likely to be violated when market sentiment is more exuberant or when the market has a higher probability of crashing.

Proposition 5 The expected gain to regular investors of deviating from the inventory holding strategy and selling shares at $t=1$,

$$
\gamma q_{2}^{*}(a, \gamma)\left(a-\lambda\left(q_{1}^{*}(a, \gamma)+q_{2}^{*}(a, \gamma)\right)\right)
$$

is increasing in a and $\gamma$. Thus, if constraint (6) is violated at $\left(q_{1}^{*}, q_{2}^{*}\right)$ for some $a=\hat{a}$ and $\gamma=\hat{\gamma}$, then it will be violated for all $a>\hat{a}$ and $\gamma>\hat{\gamma}$.

Proof. See the appendix.

The gain from deviating from the inventory holding strategy depends on the product of $q_{2}$ and $\left(P_{1}-V_{R}\right)$. An increase in $a$ increases both (Proposition 4), increasing the incentive to deviate as indicated in Proposition 5. Similarly, an increase in the probability of crash $\gamma$ increases the incentive of regular investors to deviate and sell their entire allocation of IPO shares at $t=1$.

The issuer's constrained problem is to solve the following:

$$
\begin{aligned}
& \max _{q_{1}, q_{2}}\left(q_{1}+(1-\gamma) q_{2}\right)\left(a-\lambda\left(q_{1}+q_{2}\right)\right) \\
& \text { s.t. } R \geq \gamma q_{2}\left(a-\lambda\left(q_{1}+q_{2}\right)\right) .
\end{aligned}
$$

Let the solution to the above programming problem be $\left(q_{1}^{c}, q_{2}^{c}\right)$. The next proposition characterizes the quantities chosen by the issuer.

Proposition 6 If the optimal $\left(q_{1}^{*}, q_{2}^{*}\right)$ defined in Proposition 2 are such that (6) is violated, then the optimal choice of shares issued $\left(q_{1}^{c}, q_{2}^{c}\right)$ is given by

$$
\begin{aligned}
& q_{1}^{c}=\bar{Q}_{1} \\
& q_{2}^{c}=\frac{1}{2 \lambda}\left(\left(a-q_{1} \lambda\right)-\sqrt{\left.\left(a-q_{1} \lambda\right)^{2}-\frac{4 R \lambda}{\gamma}\right)} .\right.
\end{aligned}
$$

Proof. See the appendix. 
The optimal quantity sold in the secondary market at $t=1$ is the same as that in the unconstrained case presented earlier. This is because if the underwriter sells more than $\bar{Q}_{1}$ at $t=1$, the marginal investor is no longer a sentiment investor but instead a rational institutional investor. Selling to rational investors at $t=1$ forces the firm to sell to sentiment investors at a price lower than that of the marginal sentiment investor, which is not wealth maximizing. However, constraint (6) does decrease the quantity sold at $t=2$, and consequently, the total quantity sold. This distortion in $q_{2}$ is highest for underwriters with a small $R$.

As can be seen from (7), an increase in $R$ is associated with an increase in $q_{2}$. With a greater amount of potential rent at stake, it is incentive compatible for regular investors to carry more IPO shares in inventory. Therefore, if periods of high IPO volume imply larger $R$, the size of the IPOs will also be larger, ceteris paribus. Similarly, underwriters who have a larger (expected) market share can impose bigger penalties, i.e. they have a higher $R$. All else equal, this allows them to increase the size of the offering. Thus, growth will beget more growth and a hot market will get hotter. This suggests that a hot market can have a certain self-fulfilling logic. In the next proposition we present comparative statics of various IPO price patterns, when the inventory holding constraint is binding.

Proposition 7 If the number of shares issued $Q$ is such that regular investors' inventory holding constraint is binding, then

1. the initial day return $\left(\frac{P_{1}-P_{0}}{P_{0}}\right)$ is increasing in $R$, a and $\gamma$;

2. long-run underperformance is decreasing in $R$ and increasing in a and $\gamma$; and

3. the ratio of the initial price run-up to long-run underperformance is increasing in $R$ and $\gamma$ and decreasing in a.

Proof. See the appendix.

The initial price run-up serves as a form of compensation to the institutional investors for carrying inventory. An offering by an underwriter with a lower $R$ is smaller in size and 
has a higher $P_{1}$. Thus, if the inventory holding constraint is binding, a higher $R$ increases the compensation that institutional investors require, resulting in higher $q_{2}$ and a lower $P_{1}$. Thus, institutional investors need not be compensated to the same extent for carrying the inventory to $t=2$. It is also immediate that lower $R$ offerings will tend to be associated with greater underperformance since a decrease in $R$ is associated with a decrease in $q_{2}$ and, thereby, an increase in $P_{1}$. This is generally consistent with the empirical evidence that IPOs done by larger, established underwriters tend to exhibit less underperformance.

If one interprets $R$ as also being lower toward the end of a hot market (since investors expect the volume of IPOs to fall) and, possibly, just before the hot market gets going, then the predictions above can be viewed as being consistent with greater underpricing and poorer underperformance at the end of a hot market and possibly in the initial period as well. We discuss this and other empirical implications of the model in the next section.

\section{Empirical Implications}

The model has a number of empirical implications, some of which have already been mentioned. We now collect these and other empirical implications. Several of them are consistent with existing empirical evidence, while others are in the nature of new predictions.

Prediction 1 (Partial Adjustment) As the difference in opinion between rational and sentiment investors increases, both the offer price and underpricing increase.

This follows directly from Proposition 4. An increase in $a$, reflecting an increase in the optimism of sentiment investors, results in an increase in the offer price $P_{0}$ and in the initial price run-up. Prediction 1 implies a positive correlation between pre-market changes in the offer price and after-market underpricing. This is consistent with the empirical evidence presented in Hanley (1993) and Ljungqvist, Jenkinson, and Wilhelm (2001) who show that underpricing is higher, the more the offer price exceeds the midpoint of the original indicative price range. This 'partial adjustment' phenomenon is often viewed as supporting the information acquisition model of Benveniste and Spindt (1989): to induce truthful revelation, underwriters must leave more money on the table in states of the world 
where investors hold particularly positive information. Our model provides an alternative rationale for the partial adjustment phenomenon based on the difference in opinion between the sentimental and rational investors. Since our model does not rely on private information, it can accommodate Loughran and Ritter's (2001) finding of partial adjustment to public information.

To see what is driving partial adjustment - increases in investor optimism or information acquisition - requires a measure of the degree of divergence of opinion in the IPO market. Aggarwal and Conroy (2000) propose time-to-first-trade as a proxy: delaying the first trade may enable the underwriter to better gauge market demand and could thus be an indication of greater initial divergence of opinion. They document that underpricing increases in timeto-first-trade, consistent with our prediction that underpricing increases in the degree of divergence of opinion in the IPO market. However, whether this is behind the partial adjustment phenomenon remains to be investigated.

Prediction 2 As the difference in opinion between rational and sentiment investors increases, long-run performance is lower.

This follows from Propositions 4 and 7. Dunbar (1998) finds that IPOs with positive price and offer size adjustments are prone to poor long-run performance and conjectures that this is evidence of "excess initial retail investor demand."

Prediction 3 The relation between long-run performance and the initial price run-up is non-monotonic. It is negative if the probability of the hot market ending is small.

This follows from Propositions 4 and 7. Ritter (1991) finds weak evidence that underpricing and long-run performance are negatively correlated, consistent with this prediction. In particular, he shows that long-run performance is particularly poor amongst smaller issuers, which tend to have the highest initial returns. Krigman, Shaw, and Womack (1999), on the other hand, find a positive relation between underpricing and one-year returns, except for 'extra-hot' IPOs: offerings with initial returns in excess of $60 \%$ have the worst one-year performance in their sample.

Prediction 4 Long-run performance is negatively related to the initial extent of diver- 
gence of opinion.

Like Prediction 1, this prediction requires a measure of divergence of opinion. Using Aggarwal and Conroy's time-to-first-trade proxy, Houge, Loughran, Suchanek, and Yan (2000) show that late-opening IPOs significantly underperform over the subsequent three years. Houge et al. further analyze the relation between long-run performance and the size of the bid-ask spread set by market-makers when the IPO opens. The bid-ask spread should at least in part reflect the market-maker's uncertainty regarding a company's value. Consistent with this interpretation, Houge et al. find that subsequent abnormal performance decreases in the opening spread.

In our model, as $\gamma$, the likelihood of the hot market ending, increases regular investors hold less inventory, indicating that a relatively larger fraction of the allocation is flipped. This is consistent with the results in Krigman, Shaw, and Womack (1999). Using the ratio of sell-initiated large-block trading volume to total volume traded on the first day as a measure of the sentiment of institutions, they find that IPOs which are flipped more on the first day underperform low-flipping IPOs over the next twelve months.

Rajan and Servaes (1997) look at analyst following after the IPO and find that not only were analysts over-optimistic about earnings and long-term growth prospects, but issuers may also have taken advantage of windows of opportunity: more companies went public when analysts where particularly over-confident about recent IPOs in the same industry. Interestingly, IPOs with low forecast growth rates subsequently out-performed IPOs with high forecast growth rates, by a margin of more than $100 \%$ over five years. To the extent the forecasts reflected some of the optimism of the sentiment investors, these findings are consistent with our prediction.

\section{The dynamics of the IPO market cycle}

Prediction 5 As the optimism of sentiment investors increases, more companies have the incentive to go public (to take advantage of the optimistic investors) and offer sizes increase.

Consistent with this prediction, Lee, Shleifer, and Thaler (1991) show that the annual 
number of IPOs between 1966 and 1985 was strongly negatively related to the discount on closed-end mutual funds, which they argue is a measure of the sentiment of retail investors.

Lowry and Schwert (2000) show that following periods of 'unusually' high underpricing, both IPO volume and IPO registrations increase and that companies which are already in SEC registration accelerate the completion of their IPOs. This is consistent with the first part of Prediction 5.

We know of no existing evidence regarding changes in offer size over the IPO market cycle. In our model, greater optimism amongst sentiment investors predicts a larger optimal offer size.

Prediction 6 As the IPO market heats up, lower-quality companies are taken public resulting in a decline in the quality of the average issuer.

Ritter (1991) argues that companies which went public in the hot market of the early 1980s performed particularly badly in the long-run, consistent with a decline in issuer quality. Loughran and Ritter (1995) likewise note that subsequent stock price performance was significantly lower for companies going public in hot markets. Helwege and Liang (1996) investigate this claim further, by examining the quality of IPO firms in 'hot' and 'cold' markets. Interestingly, they find no difference in operating performance (their measure of issuer quality) between hot-market and cold-market issuers, though they do corroborate Loughran and Ritter's (1995) claim that hot-market issuers have worse stock-price returns. Loughran and Ritter (2000) find strong evidence that companies going public in highvolume periods experience significantly worse long-run performance than those floated in low-volume periods. They view this finding as evidence of issuers taking advantage of periods of misvaluation.

The hot market of 1998-2000 may be a good illustration of the evolution of issuer quality over the IPO market cycle. ${ }^{15}$ According to Ritter and Welch (2001), 66\% of firms listing

\footnotetext{
15 "It's no secret: greedy investment banks fattened their wallets last year by taking marginal companies public. They set ridiculous prices and pumped up shares in the aftermarket to ludicrously unsustainable levels. The bankers salted away hefty 7 percent commissions for merely 'allocating' - rather than working to sell - new shares in oversubscribed offerings. Institutional investors who flipped the stocks on their opening days reaped triple-digit returns. Even the issuing companies that sold stock that was undervalued at the
} 
in the U.S. in 1997 had 12-month track records of earnings; by 1999 this had fallen to just $23 \%$.

Prediction 7 As the IPO market heats up, companies are more likely to raise money for non-investment purposes, such as paying down debt.

This prediction is based on Prediction 6, insofar as a hot market will attract opportunistic issuers. We know of no existing evidence pertaining to this prediction.

Prediction 8 When the hot market is just starting or is petering out, $R$ may be lower. If so, initial returns and long-run underperformance may both be larger toward the beginning and the end of a hot market.

The only existing evidence, discussed earlier, compares initial and long-run returns in 'hot' and 'cold' markets. A direct test of Prediction 8 requires a methodology for determining when, exactly, a hot market begins or ends.

\section{The role of the underwriter}

Prediction 9 More prestigious underwriters have access to higher IPO deal flow and so have higher $R$. Higher $R$, in turn, leads to larger initial price run-ups and lower underperformance.

The evidence on underpricing is mixed. Contrary to our prediction, Carter and Manaster (1990) and Carter, Dark, and Singh (1998) find that more prestigious underwriters are associated with lower underpricing. Beatty and Welch (1996), on the other hand, point out that this relation appears to be reversed in the 1990s. Habib and Ljungqvist (2001) show that the apparent reversal is driven, at least in part, by the failure to treat the choice of underwriter as endogenous.

Prediction 9 applies in particular to hot markets whereas none of the above papers control for the state of the IPO market. Benveniste, Ljungqvist, Wilhelm, and Yu (2001) find a positive relation between underpricing and underwriter prestige in the 1999/2000 hot market, consistent with our prediction.

time got way more than they deserved." Tom Davey, 'IPO Critic: The IPO hangover', Red Herring, April 23,2001 . 
Furthermore, Carter, Dark, and Singh (1998) show that IPOs lead-managed by more prestigious underwriters are associated with lower underperformance over the next three years.

\section{Supporting the equilibrium}

Prediction 10 (Allocation policy) Underwriters have a preference for selling to regular (typically institutional) investors.

This prediction follows because the repeated interaction with regular investors, and the ease of tracking larger positions, will lower the costs of sustaining the equilibrium. Empirical evidence suggests that IPO allocations are heavily skewed in favor of institutional investors [Hanley and Wilhelm (1995), Ljungqvist and Wilhelm (2001)] and that regular investors are favored over infrequent investors [Cornelli and Goldreich (2000)]. Ang, Brau, and Ljungqvist (2001) show that in offers marketed to both institutional and retail investors, the more retail demand the underwriter can generate, the more aggressively the issue is priced and so the lower is underpricing. This is consistent with the structure of our model in that an underwriter will want to use his regular investors repeatedly as this allows him to offer IPOs at higher prices.

Prediction 11 (Flipping) Underwriters penalize investors who engage in excessive flipping (relative to the optimal selling strategy).

The prediction is consistent with the use of penalty bids [Aggarwal (2000)] which underwriters impose on syndicate members whose clients flip their allocations. Subtler penalties include exclusion from future IPO offerings. Such penalties are usually viewed as part and parcel of price support. Our model predicts that the penalties should occur more widely than in IPOs which receive price support. This remains to be tested.

Prediction 12 (Flipping) Penalties for excessive flipping are targeted more heavily at retail and infrequent investors.

In order to sustain the equilibrium, underwriters need to ensure that their regular investors do not make (excessive) losses on their holdings between dates 1 and 2. Competing 
selling pressure from investors who are not party to the equilibrium strategy would therefore undermine the equilibrium. Articles in the business press provide some anecdotal support for Prediction 12: "When a stock quadruples on its first day of trading, many stockholders want to sell, or flip, their shares [...]. They can, if they are big investors or mutual funds that have close ties with the underwriter. [...] But underwriters force most individual investors - and even money managers without much clout - to hold on to their shares for as long as 90 days." 16

Such practices have attracted the attention of securities regulators. In August 1998, the SEC "launched an inquiry into how brokerage firms seek to bar small investors from flipping [...] initial public offerings, but allow institutional investors to flip hot new stocks with impunity." 17 At the same time, Massachusetts regulators fined Joseph Charles and Associates, a Florida-based underwriter, $\$ 50,000$ and barred it from doing business in the state for two years, because of the bank's policy against flipping by retail investors. Our analysis suggests that Massachusetts may want to reconsider its policy - since such practices induce more firms to go public and sell their equity at a more attractive price.

Prediction 13 (Post-IPO sales) Over time institutional investors unload their excess inventory. Hence, we predict a gradual divestment of IPO shares held by institutions and an increase in the shares held by retail investors.

Boehmer and Fishe (2001) find that more than $92 \%$ of all first-day flipping transactions by investors who were allocated stock in the IPO are smaller than 10,000 shares. This strongly suggests that the buyers in these transactions are retail investors. There is more flipping in more underpriced offerings, consistent with our model.

Field (1995) shows that long-run performance is better, the larger institutional stockholdings at the end of the first quarter of listing. Field does not have data on allocations, but her evidence is consistent with the prediction that institutions quickly sell out of the more marginal IPOs, so that by quarter's end they hold more stock in the higher-quality

\footnotetext{
${ }^{16}$ E. Leefeldt, "Fixed rates, double standards", Bloomberg, May 2000, pp. 36-40.

${ }^{17}$ M. Siconolfi, "SEC launches probe into IPO flipping - state regulators fire 1 st volley in matter." The Wall Street Journal, August 20, 1998.
} 
companies.

Prediction 14 (Lock-ups) Lock-up provisions ensure that regular investors do not face competition from insiders when selling inventory to sentiment investors at $t=2$.

Several recent papers have documented that share prices fall significantly upon the expiry of lock-up provisions [Field and Hanka (2001), Brav and Gompers (2000), Ofek and Richardson (2000)], but their purpose has not been modeled. In our model such lockups may serve to reassure institutional investors of their ability to sell at high prices in subsequent periods if the hot market persists, without having insiders satisfy part of the demand by sentiment investors.

Prediction 15 (Lock-ups) Insiders will be released early from their lock-up provisions, a) if after-market demand from sentiment investors is unexpectedly high, b) once regular investors have unloaded their excess inventory, or c) if the hot market has come to an end.

According to Brav and Gompers (2000), early release is common: $60 \%$ of the firms in their sample have insiders sell shares prior to the lock-up expiry. The determinants of early release remain to be investigated. Our model suggests that such a release may be more likely under the circumstances mentioned.

Prediction 16 (Lock-ups) The price impact of insider sales upon lock-up expiry is expected to be negative, particularly if it follows a strong post-IPO stock performance.

This prediction follows from the downward sloping nature of the demand by sentiment investors: as insiders sell to take advantage of the high prices, the price is expected to fall. We would expect such sales to be more likely if the market heats up even further and the marginal investor continues to be a sentiment investor. Field and Hanka (2001) report that the average price impact of lock-up expiry is a decline of $2 \%$.

Prediction 17 (Price support) If demand by sentiment investors turns out to be unexpectedly low in the early after-market, the underwriter may want to absorb the excess supply by providing price support. The main beneficiaries of price support are the underwriter's regular investors. 
Benveniste, Erdal, and Wilhelm (1998) find that it is overwhelmingly large (presumably institutional) traders who execute sell orders in stabilized offerings, rather than small (presumably retail) traders. They interpret this finding as indicating that price support is offered mainly for the benefit of institutional investors. This is consistent with our underlying assumption that underwriters and large investors collude to extract value from sentiment investors.

Unexpectedly low demand at $t=1$ does not necessarily mean that total demand by sentiment investors will be low. Thus, price support may well be profitable when there are unexpectedly many late-arriving sentiment investors at $t=2$. Ellis, Michaely, and O'Hara (2000) investigate the profits of underwriters who act as market makers for their IPOs. The somewhat surprising fact that market makers' inventory losses do not differ between hot and cold deals might be due to profitable trades with late-arriving sentiment investors.

\section{Conclusions}

Our model of the IPO process links the three main empirical IPO 'anomalies' - underpricing, hot issue markets, and long-run underperformance - and traces them to a common source of inefficiency. As the discussion in the previous section shows, the model is consistent with much of the - at times seemingly contradictory - evidence. The model also generates new predictions about the IPO process which can potentially be used to refute it.

The key to the emergence of a hot market in our model is the increase in optimism of sentiment traders. We are agnostic about what might cause such an increase and thus whether swings in the IPO market are predictable. 


\section{Appendix}

\section{Proof of Proposition 1:}

For a given $Q>\bar{Q}_{1}$, suppose $q_{1}^{*}>\bar{Q}_{1}$. Consider $\hat{q}_{1}=\bar{Q}_{1}$ and adjusting $q_{2}$ to $\hat{q}_{2}$ such that $\hat{q}_{1}+\hat{q}_{2}=Q . \quad P_{2}$ is unchanged, as it is a function of $Q$. However, from (2), $P_{1}\left(\hat{q}_{1}\right)>P_{1}\left(q_{1}^{*}\right)$. Thus, $\Pi\left(\hat{q}_{1}\right)>\Pi\left(q_{1}^{*}\right)$. Similarly, for a given $Q>\bar{Q}_{1}$, suppose $q_{1}^{*}<\bar{Q}_{1}$. Consider $\hat{q}_{1}=\bar{Q}_{1}$ and adjusting $q_{2}$ to $\hat{q}_{2}$ such that $\hat{q}_{1}+\hat{q}_{2}=Q . E\left(P_{2}\right)$ is unchanged, as it is a function of $Q$. In this case $P_{1}=E^{s}\left(P_{2}\right)$, which is greater than $E^{R}\left(P_{2}\right)$. Thus, expected $\Pi$ increases by $\left(E^{s}\left(P_{2}\right)-E\left(P_{2}\right)\right)\left(\bar{Q}_{1}-q_{1}^{*}\right)$. Hence, $q_{1}^{*} \neq \bar{Q}_{1}$ cannot be optimal. If $Q \leq \bar{Q}_{1}$, the non-negativity for $q_{2}$ implies $q_{1}^{*}=Q$ and $q_{2}^{*}=0$.

\section{Proof of Proposition 4:}

We analyze the case when $\bar{Q}_{1}$ is small enough such that $q_{2}^{*}>0$. Substituting for $q_{1}$ and $q_{2}$ in $P_{1}=a-\lambda\left(q_{1}+q_{2}\right)+V_{R}$ we obtain

$$
P_{1}=\frac{a}{2}+\frac{\lambda \gamma}{2(1-\gamma)} \bar{Q}_{1}+V_{R}
$$

which is increasing in $\gamma$ and $a$. Now consider the long-run performance $\left(\frac{P_{1}-V_{R}}{P_{1}}\right)$.

$$
\begin{aligned}
& \operatorname{sign}\left[\frac{\partial}{\partial a}\left(\frac{P_{1}-V_{R}}{P_{1}}\right)\right]=\operatorname{sign}\left[\frac{\partial P_{1}(a)}{\partial a} \frac{V_{R}}{P_{1}(a)^{2}}\right]=\operatorname{sign}\left[\frac{\partial P_{1}(a)}{\partial a}\right] \\
& \operatorname{sign}\left[\frac{\partial}{\partial \gamma}\left(\frac{P_{1}-V_{R}}{P_{1}}\right)\right]=\operatorname{sign}\left[\frac{\partial P_{1}(\gamma)}{\partial \gamma} \frac{V_{R}}{P_{1}(\gamma)^{2}}\right]=\operatorname{sign}\left[\frac{\partial P_{1}(\gamma)}{\partial \gamma}\right]
\end{aligned}
$$

Thus, long-run underperformance is increasing in $\gamma$ and $a$.

From Proposition 3 the ratio of the initial price run-up to long-run underperformance is given by

$$
\frac{P_{1}-P_{0}}{P_{1}-V_{R}}=\frac{\gamma q_{2}}{Q}=\frac{\gamma q_{2}}{q_{1}+q_{2}} .
$$

Taking the derivative w.r.t. $a$ we get

$$
\begin{aligned}
\frac{\partial}{\partial a}\left(\frac{P_{1}-P_{0}}{P_{1}-V_{R}}\right) & =\gamma \frac{\partial}{\partial a}\left(\frac{q_{2}}{q_{1}+q_{2}}\right) \\
& =\frac{\gamma q_{1}}{\left(q_{1}+q_{2}\right)^{2}}>0
\end{aligned}
$$


The ratio of the initial price run-up to long-run underperformance is not monotonic in $\gamma$.

To see this, note that $q_{2}=0$ at $\gamma=\frac{a-2 q_{1} \lambda}{a-q_{1} \lambda}$. Thus,

$$
\frac{P_{1}-P_{0}}{P_{1}-V_{R}}=\frac{\gamma q_{2}}{q_{1}+q_{2}}=\left\{\begin{array}{ccc}
0 & \text { for } & \gamma=0 \\
0 & & \gamma=\frac{a-2 q_{1} \lambda}{a-q_{1} \lambda}
\end{array}\right.
$$

and $\frac{P_{1}-P_{0}}{P_{1}-V_{R}}>0$ for $\gamma \in\left(0, \frac{a-2 q_{1} \lambda}{a-q_{1} \lambda}\right)$. The derivative of the ratio is:

$$
\begin{aligned}
\frac{\partial}{\partial \gamma}\left(\frac{\gamma q_{2}}{q_{1}+q_{2}}\right)= & \frac{q_{2}}{q_{1}+q_{2}}+\gamma\left(\frac{q_{1}}{\left(q_{1}+q_{2}\right)^{2}}\right) \frac{\partial q_{2}}{\partial \gamma} \\
\operatorname{sign}\left[\frac{\partial}{\partial \gamma}\left(\frac{\gamma q_{2}}{q_{1}+q_{2}}\right)\right] & =\operatorname{sign}\left[q_{2}\left(q_{1}+q_{2}\right)+\gamma q_{1} \frac{\partial q_{2}}{\partial \gamma}\right] \\
& =\operatorname{sign}\left[q_{2}\left(q_{1}+q_{2}\right)-\frac{\gamma q_{1}^{2}}{2(1-\gamma)^{2}}\right]
\end{aligned}
$$

The above is positive at $\gamma=0$ and negative at $\gamma=\frac{a-2 q_{1} \lambda}{a-q_{1} \lambda}$ as $q_{2}=0$. The second derivative is given by

$$
\begin{aligned}
\frac{\partial^{2}}{\partial \gamma^{2}}\left(\frac{\gamma q_{2}}{q_{1}+q_{2}}\right) & =\frac{q_{1}}{\left(q_{1}+q_{2}\right)^{3}}\left(2\left(q_{1}+q_{2}\right) \frac{\partial q_{2}}{\partial \gamma}+\gamma\left(q_{1}+q_{2}\right) \frac{\partial^{2} q_{2}}{\partial \gamma^{2}}-2 g\left(\frac{\partial q_{2}}{\partial \gamma}\right)^{2}\right) \\
& <0\left[\text { As } \frac{\partial q_{2}}{\partial \gamma}<0 \text { and } \frac{\partial^{2} q_{2}}{\partial \gamma^{2}}=-\frac{q_{1}}{(1-\gamma)^{3}}<0\right]
\end{aligned}
$$

Thus, there exists a $\hat{\gamma}$ such that for all $\gamma<\hat{\gamma}, \frac{\partial}{\partial \gamma}\left(\frac{P_{1}-P_{0}}{P_{1}-V_{R}}\right)>0$ and for $\gamma>\hat{\gamma}, \frac{\partial}{\partial \gamma}\left(\frac{P_{1}-P_{0}}{P_{1}-V_{R}}\right)<$ 0.

The initial price run-up $\left(\frac{P_{1}-P_{0}}{P_{0}}\right)$ is monotonic in $a$. To see this, examine

$$
\begin{gathered}
P_{0}=P_{1}-\frac{\gamma q_{2}}{Q}\left(P_{1}-V_{R}\right) \\
\frac{P_{0}}{P_{1}}=1-\frac{\gamma q_{2}}{Q}\left(1-\frac{V_{R}}{P_{1}}\right) \\
\operatorname{sign}\left[\frac{\partial}{\partial a}\left(\frac{P_{1}-P_{0}}{P_{0}}\right)\right]=-\operatorname{sign}\left[\frac{\partial}{\partial a}\left(\frac{P_{0}}{P_{1}}\right)\right] \\
=-\operatorname{sign}\left[-\left(1-\frac{V_{R}}{P_{1}}\right) \frac{\partial}{\partial a}\left(\frac{q_{2}}{q_{1}+q_{2}}\right)+\frac{V_{R} q_{2}}{q_{1}+q_{2}} \frac{\partial}{\partial a}\left(\frac{1}{P_{1}}\right)\right] \\
=\operatorname{sign}\left[\left(1-\frac{V_{R}}{P_{1}}\right) \frac{\partial}{\partial a}\left(\frac{q_{2}}{q_{1}+q_{2}}\right)-\frac{V_{R} q_{2}}{q_{1}+q_{2}} \frac{\partial}{\partial a}\left(\frac{1}{P_{1}}\right)\right] \\
=\operatorname{positive}
\end{gathered}
$$


The above uses the following:

$$
\begin{aligned}
\frac{\partial}{\partial a}\left(\frac{q_{2}}{q_{1}+q_{2}}\right) & =\frac{\partial q_{2}(a)}{\partial a} \frac{q_{1}}{\left(q_{1}+q_{2}(a)\right)^{2}}>0 \\
\frac{\partial}{\partial a}\left(\frac{1}{P_{1}}\right) & <0 \\
\left(1-\frac{V_{R}}{P_{1}}\right) & >0 .
\end{aligned}
$$

Similarly,

$$
\begin{aligned}
\operatorname{sign}\left[\frac{\partial}{\partial \gamma}\left(\frac{P_{1}-P_{0}}{P_{0}}\right)\right] & =-\operatorname{sign}\left[\frac{\partial}{\partial \gamma}\left(\frac{P_{0}}{P_{1}}\right)\right] \\
& =\operatorname{sign}\left[\left(1-\frac{V_{R}}{P_{1}}\right) \frac{\partial}{\partial \gamma}\left(\frac{\gamma q_{2}}{q_{1}+q_{2}}\right)-\frac{V_{R} \gamma q_{2}}{q_{1}+q_{2}} \frac{\partial}{\partial \gamma}\left(\frac{1}{P_{1}}\right)\right]
\end{aligned}
$$

The second term is positive and so is the first for $\gamma<\hat{\gamma}$. Thus, for low $\gamma$ the initial price run-up is increasing in $\gamma$.

\section{Proof of Proposition 5:}

Taking the derivative of the RHS of the constraint in (6) w.r.t. $a$ we obtain

$$
\begin{aligned}
& \operatorname{sign}\left[\frac{\partial}{\partial a} \gamma q_{2}^{*}(a, \gamma)\left(a-\lambda\left(q_{1}^{*}(a, \gamma)+q_{2}^{*}(a, \gamma)\right)\right)\right] \\
& =\operatorname{sign}\left[\left(a-\lambda \bar{Q}_{1}-2 q_{2}^{*} \lambda\right) \frac{\partial q_{2}^{*}}{\partial a}\right] \\
& =\text { positive }
\end{aligned}
$$

Thus, as if the constraint binds for some $a$ then it will also bind for all higher $a$.

The constraint can bind only if $q_{2}>0$, i.e. $\bar{Q}_{1}<\frac{a(1-g)}{\lambda(2-g)}$. Let $\bar{Q}_{1}=\beta \frac{a(1-g)}{\lambda(2-g)}$ where $\beta<1$. Substituting in the constraint we get

$$
\begin{aligned}
& \gamma q_{2}^{*}(a, \gamma)\left(a-\lambda\left(q_{1}^{*}(a, \gamma)+q_{2}^{*}(a, \gamma)\right)\right) \\
& =\gamma\left(\frac{a}{2 \lambda}-\bar{Q}_{1}\left(1+\frac{\gamma}{2(1-\gamma)}\right)\right)\left(\frac{a}{2}+\bar{Q}_{1} \frac{\gamma \lambda}{2(1-\gamma)}\right) \\
& =\gamma\left(\frac{a}{2 \lambda}-\beta \frac{a(1-\gamma)}{\lambda(2-\gamma)}\left(1+\frac{\gamma}{2(1-\gamma)}\right)\right)\left(\frac{a}{2}+\beta \frac{a(1-\gamma)}{\lambda(2-\gamma)} \frac{\gamma \lambda}{2(1-\gamma)}\right) \\
& =\frac{\gamma}{4 \lambda}\left(a-\beta \frac{2 a(1-\gamma)}{(2-\gamma)}-\beta \frac{a \gamma}{(2-\gamma)}\right)\left(a+\beta \frac{a \gamma}{(2-\gamma)}\right)
\end{aligned}
$$


Taking the derivative of the above w.r.t. to $\gamma$, we obtain

$$
a^{2}(1-\beta) \frac{4(1-\gamma)+\gamma^{2}(1-\beta)+4 \beta \gamma}{(2-\gamma)^{2}}>0
$$

\section{Proof of Proposition 6:}

If the constraint binds at $\left(q_{1}^{*}, q_{2}^{*}\right)$ then $q_{2}^{*} \geq 0$, which implies that $q_{1}^{*}=\bar{Q}_{1}$. Similar to the argument provided in Proposition 1, it is easy to see that $q_{1}^{c}=q_{1}^{*}=\bar{Q}_{1}$. The optimal $q_{2}$ if the penalty constraint binds is one of the two solutions to the following quadratic:

$$
R=q_{2} \gamma\left(a-\lambda\left(q_{1}+q_{2}\right)\right)
$$

Solving for $q_{2}$ we obtain

$$
q_{2}=\frac{1}{2 \lambda}\left(\left(a-q_{1} \lambda\right) \pm \sqrt{\left(a-q_{1} \lambda\right)^{2}-\frac{4 R \lambda}{\gamma}}\right) .
$$

Calculating the objective function at the above two solutions, we can show that the deference in value of the objective function at $q_{2}=\frac{1}{2 \lambda}\left(\left(a-q_{1} \lambda\right)-\sqrt{\left(a-q_{1} \lambda\right)^{2}-\frac{4 R \lambda}{\gamma}}\right)$ and the value of the objective function at $q_{2}=\frac{1}{2 \lambda}\left(\left(a-q_{1} \lambda\right)+\sqrt{\left(a-q_{1} \lambda\right)^{2}-\frac{4 R \lambda}{\gamma}}\right)$ is $q_{1} \sqrt{\left(a-q_{1} \lambda\right)^{2}-\frac{4 R \lambda}{\gamma}}$, which is positive. Hence, the constrained optimal value of $q_{2}$ is the one given in the statement of the proposition.

\section{Proof of Proposition 7:}

In the proof we use $q_{1}$ and $q_{2}$ instead of $q_{1}^{c}$ and $q_{2}^{c}$ respectively. When $R$ is binding then

$$
\gamma q_{2}\left[P_{1}-V_{R}\right]=R
$$

and

$$
q_{2}=\frac{1}{2 \lambda}\left(\left(a-q_{1} \lambda\right)-\sqrt{\left(a-q_{1} \lambda\right)^{2}-\frac{4 R \lambda}{\gamma}}\right) .
$$

Substituting $q_{2}$ in $P_{1}$ we get

$$
P_{1}=\frac{a-q_{1} \lambda}{2}+\frac{1}{2} \sqrt{\left(a-q_{1} \lambda\right)^{2}-\frac{4 R \lambda}{\gamma}}+V_{R}
$$


which is increasing in $a$ and $\gamma$, and decreasing in $R$.

$$
\operatorname{sign}\left[\frac{\partial}{\partial a}\left(\frac{P_{1}-V_{R}}{P_{1}}\right)\right]=\operatorname{sign}\left[\frac{\partial P_{1}(a)}{\partial a} \frac{V_{R}}{P_{1}(a)^{2}}\right]=\operatorname{sign}\left[\frac{\partial P_{1}(a)}{\partial a}\right]
$$

Thus, long-run underperformance is increasing in $a$. We can similarly show that long-run performance is also increasing in $\gamma$, and decreasing in $R$.

Now consider the ratio of the initial price run-up to underperformance:

$$
\begin{aligned}
\operatorname{sign}\left[\frac{\partial}{\partial \gamma}\left(\frac{P_{1}-P_{0}}{P_{1}-V_{R}}\right)\right] & =\operatorname{sign}\left[\frac{\partial}{\partial \gamma}\left(\frac{\gamma q_{2}}{q_{1}+q_{2}}\right)\right] \\
& =\operatorname{sign}\left[\frac{\partial}{\partial \gamma}\left(\frac{R}{\left(q_{1}+q_{2}\right)\left(P_{1}-V_{R}\right)}\right)\right] \\
& =-\operatorname{sign}\left[\frac{\partial}{\partial \gamma}\left(\left(q_{1}+q_{2}\right)\left(P_{1}-V_{R}\right)\right)\right] \\
& =-\operatorname{sign}\left[\frac{\partial}{\partial \gamma}\left(a\left(q_{1}+q_{2}\right)-\lambda\left(q_{1}+q_{2}\right)^{2}\right)\right] \\
& =-\operatorname{sign}\left[a \frac{\partial q_{2}}{\partial \gamma}-2 \lambda\left(q_{1}+q_{2}\right) \frac{\partial q_{2}}{\partial \gamma}\right] \\
& =\operatorname{sign}\left[a-2 \lambda\left(q_{1}+q_{2}\right)\right]
\end{aligned}
$$

The above is positive because in the unconstrained case $\Pi^{\prime}\left(q_{2}\right)>0$, where

$$
\begin{aligned}
& \frac{\partial}{\partial q_{2}}\left[q_{1} P_{1}+q_{2} P_{1}(1-\gamma)+q_{2} V_{R} \gamma-V_{R}\left(q_{1}+q_{2}\right)\right]>0 \\
& \Rightarrow \frac{\partial}{\partial q_{2}}\left[\left(q_{1}+q_{2}(1-\gamma)\right)\left(P_{1}-V_{R}\right)\right]>0 \\
& \Rightarrow(1-\gamma)\left(P_{1}-V_{R}\right)-\lambda\left(q_{1}+q_{2}(1-\gamma)\right)>0 \\
& \Rightarrow(1-\gamma)\left(a-\lambda\left(q_{1}+q_{2}\right)\right)-\lambda\left(q_{1}+q_{2}(1-\gamma)\right)>0 \\
& \Rightarrow(1-\gamma)\left(a-\lambda\left(q_{1}+q_{2}\right)\right)-\lambda\left(q_{1}+q_{2}\right)(1-\gamma)-\lambda \gamma q_{1}>0 \\
& \Rightarrow(1-\gamma)\left(a-2 \lambda\left(q_{1}+q_{2}\right)\right)-\lambda \gamma q_{1}>0 \\
& \Rightarrow\left(a-2 \lambda\left(q_{1}+q_{2}\right)\right)>0
\end{aligned}
$$

Next we show that the ratio is decreasing in $a$ and increasing in $R$.

$$
\begin{aligned}
\operatorname{sign}\left[\frac{\partial}{\partial a}\left(\frac{P_{1}-P_{0}}{P_{1}-V_{R}}\right)\right] & =\operatorname{sign}\left[\frac{\partial}{\partial a}\left(\frac{\gamma q_{2}}{q_{1}+q_{2}}\right)\right] \\
& =\operatorname{sign}\left[\frac{\gamma q_{1}}{\left(q_{1}+q_{2}\right)^{2}} \frac{\partial q_{2}}{\partial a}\right] \\
& =\text { negative }
\end{aligned}
$$


and

$$
\begin{aligned}
\operatorname{sign}\left[\frac{\partial}{\partial R}\left(\frac{P_{1}-P_{0}}{P_{1}-V_{R}}\right)\right] & =\operatorname{sign}\left[\frac{\partial}{\partial R}\left(\frac{\gamma q_{2}}{q_{1}+q_{2}}\right)\right] \\
& =\operatorname{sign}\left[\frac{\gamma q_{1}}{\left(q_{1}+q_{2}\right)^{2}} \frac{\partial q_{2}}{\partial R}\right] \\
& =\text { positive }
\end{aligned}
$$

To prove the comparative statics on the initial price run-up we need the following substitution:

$$
\begin{aligned}
\frac{P_{1}-P_{0}}{P_{1}-V_{R}} & =\frac{\gamma q_{2}}{q_{1}+q_{2}} \\
P_{1}-P_{0} & =\frac{\gamma q_{2}\left(P_{1}-V_{R}\right)}{q_{1}+q_{2}} \\
& =\frac{R}{\left(q_{1}+q_{2}\right)}
\end{aligned}
$$

Now we can show that the initial price run-up is increasing in $\gamma, a$ and $R$.

$$
\begin{aligned}
\operatorname{sign}\left[\frac{\partial}{\partial \gamma}\left(\frac{P_{1}-P_{0}}{P_{0}}\right)\right] & =\operatorname{sign}\left[\frac{\partial}{\partial \gamma}\left(\frac{R}{P_{0}\left(q_{1}+q_{2}\right)}\right)\right] \\
& =-\operatorname{sign}\left[\frac{\partial}{\partial \gamma}\left(P_{0}\left(q_{1}+q_{2}\right)\right)\right] \\
& =-\operatorname{sign}\left[\frac{\partial}{\partial \gamma}\left(P_{0}-V_{R}\right)\left(q_{1}+q_{2}\right)+V_{R} \frac{\partial q_{2}}{\partial \gamma}\right] \\
& =-\operatorname{sign}\left[\frac{\partial}{\partial \gamma} \Pi\left(q_{2}(\gamma)\right)+V_{R} \frac{\partial q_{2}}{\partial \gamma}\right] \\
& =-\operatorname{sign}\left[\frac{\partial \Pi}{\partial q_{2}} \frac{\partial q_{2}}{\partial \gamma}+V_{R} \frac{\partial q_{2}}{\partial \gamma}\right] \\
& =\operatorname{sign}\left[\frac{\partial \Pi}{\partial q_{2}}+V_{R}\right] \\
& =\text { positive }
\end{aligned}
$$


and

$$
\begin{aligned}
\operatorname{sign}\left[\frac{\partial}{\partial a}\left(\frac{P_{1}-P_{0}}{P_{0}}\right)\right] & =\operatorname{sign}\left[\frac{\partial}{\partial a}\left(\frac{R}{P_{0}\left(q_{1}+q_{2}\right)}\right)\right] \\
& =-\operatorname{sign}\left[\frac{\partial}{\partial a}\left(P_{0}\left(q_{1}+q_{2}\right)\right)\right] \\
& =-\operatorname{sign}\left[\frac{\partial}{\partial a}\left(P_{0}-V_{R}\right)\left(q_{1}+q_{2}\right)+V_{R} \frac{\partial q_{2}}{\partial a}\right] \\
& =-\operatorname{sign}\left[\frac{\partial}{\partial a} \Pi\left(q_{2}(\gamma)\right)+V_{R} \frac{\partial q_{2}}{\partial a}\right] \\
& =-\operatorname{sign}\left[\frac{\partial \Pi}{\partial q_{2}} \frac{\partial q_{2}}{\partial a}+V_{R} \frac{\partial q_{2}}{\partial a}\right] \\
& =\operatorname{sign}\left[\frac{\partial \Pi}{\partial q_{2}}+V_{R}\right] \\
& =\operatorname{positive}
\end{aligned}
$$

Similarly,

$$
\begin{aligned}
\operatorname{sign}\left[\frac{\partial}{\partial R}\left(\frac{P_{1}-P_{0}}{P_{0}}\right)\right] & =\operatorname{sign}\left[\frac{\partial}{\partial R}\left(\frac{R}{P_{0}\left(q_{1}+q_{2}\right)}\right)\right] \\
& =\operatorname{sign}\left[P_{0}\left(q_{1}+q_{2}\right)-R \frac{\partial}{\partial R}\left(P_{0}\left(q_{1}+q_{2}\right)\right)\right] \\
& =\operatorname{sign}\left[P_{0}\left(q_{1}+q_{2}\right)-R \frac{\partial}{\partial R}\left(\left(P_{0}-V_{R}\right)\left(q_{1}+q_{2}\right)\right)-R V_{R} \frac{\partial q_{2}}{\partial R}\right] \\
& =-\operatorname{sign}\left[\frac{\partial}{\partial}\left(P_{0}-V_{R}\right)\left(q_{1}+q_{2}\right)+V_{R} \frac{\partial q_{2}}{\partial a}\right] \\
& =-\operatorname{sign}\left[\frac{\partial}{\partial a} \Pi\left(q_{2}(\gamma)\right)+V_{R} \frac{\partial q_{2}}{\partial a}\right] \\
& =-\operatorname{sign}\left[\frac{\partial \Pi}{\partial q_{2}} \frac{\partial q_{2}}{\partial a}+V_{R} \frac{\partial q_{2}}{\partial a}\right] \\
& =\operatorname{sign}\left[\frac{\partial \Pi}{\partial q_{2}}+V_{R}\right] \\
& =\operatorname{positive}
\end{aligned}
$$




\section{References}

Aggarwal, R., 2000, 'Stabilization activities by underwriters after IPOs', Journal of Finance 55, 1075-1103.

Aggarwal, R., and P. Conroy, 2000, 'Price discovery in initial public offerings and the role of the lead underwriter', Journal of Finance 55, 2903-2922.

Allen, F., and G.R. Faulhaber, 1989, 'Signaling by underpricing in the IPO market', Journal of Financial Economics 23, 303-323.

Ang, J., J. Brau, and A.P. Ljungqvist, 2001, 'Irrational exuberance in the marketing of IPOs: "Push" created demand and the impresario hypothesis', mimeo, Stern School of Business, New York University.

Beatty, R.P., and I. Welch, 1996, 'Issuer expenses and legal liability in initial public offerings', Journal of Law and Economics 39, 545-602.

Benveniste, L.M., and P.A. Spindt, 1989, 'How investment bankers determine the offer price and allocation of new issues', Journal of Financial Economics 24, 343-361.

Benveniste, L.M., S.M. Erdal, and W.J. Wilhelm, 1998, 'Who benefits from secondary market price stabilization of IPOs?', Journal of Banking and Finance 22, 741-767.

Benveniste, L.M., A.P. Ljungqvist, W.J. Wilhelm, and X. Yu, 2001, 'Evidence of information spillovers in the production of investment banking services', mimeo, Stern School of Business, New York University.

Boehmer, E., and R.P.H. Fishe, 2001, 'Do underwriters encourage stock flipping? The link between trading profits and pricing in IPOs', mimeo, University of Miami.

Brav, A., C.C. Geczy, and P. Gompers, 2000, 'Is the abnormal return following equity issuances anomalous?', Journal of Financial Economics 56, 209-249.

Brav, A., and P. Gompers, 1997, 'Myth or reality? The long-run underperformance of initial public offerings: Evidence from venture and non-venture capital-backed companies', Journal of Finance 52, 1791-1821. 
Brav, A., and P. Gompers, 2000, 'Insider trading subsequent to initial public offerings: Evidence from expirations of lockup provisions', mimeo, Duke University.

Carter, R.B., and S. Manaster, 1990, 'Initial public offerings and underwriter reputation', Journal of Finance 45, 1045-1067.

Carter, R.B., F.H. Dark, and A.K. Singh, 1998, 'Underwriter reputation, initial returns, and the long-run performance of IPO stocks', Journal of Finance 53, 285-311.

Cornelli, F., and D. Goldreich, 2000, 'Bookbuilding and strategic allocation', forthcoming in Journal of Finance.

Daniel, K.D., D. Hirshleifer, and A. Subrahmanyam, 1998, 'Investor psychology and security market under- and overreactions', Journal of Finance 53, 1839-1886.

Dittmar, A.K., 2000, 'Why do firms repurchase stock?', Journal of Business 73, 321-356.

D’Mello, R., and P.K. Shrof, 2000, 'Equity undervaluation and decisions related to repurchase tender offers: An empirical investigation', Journal of Finance 55, 2399-2424.

Dunbar, C., 1998, 'Offer term adjustments in IPOs', mimeo, University of Western Ontario.

Eckbo, B.E., R. Masulis, and Ø. Norli, 2000, 'Seasoned public offerings: Resolution of the new issues puzzle', Journal of Financial Economics 56, 251-291.

Ellis, K., R. Michaely, and M. O'Hara, 2000, 'When the underwriter is the market maker: An examination of trading in the IPO aftermarket', Journal of Finance 55, 1039-1074.

Field, L.C., 1995, 'Is institutional investment in initial public offerings related to longrun performance of these firms?', mimeo, UCLA.

Field, L.C., and G. Hanka, 2001, 'The expiration of IPO share lockups', Journal of Finance 56, 471-500.

Geczy, C.C., D.K. Musto, and A.V. Reed, 2001, 'Stocks are special too: An analysis of the equity lending market', mimeo, University of Pennsylvania. 
Gervais, S., and T. Odean, 2001, 'Learning to be overconfident', Review of Financial Studies 14, 1-27.

Habib, M.A., and A.P. Ljungqvist, 2001, 'Underpricing and entrepreneurial wealth losses in IPOs: Theory and evidence', Review of Financial Studies 14, 433-458.

Hanley, K., 1993, 'The underpricing of initial public offerings and the partial adjustment phenomenon', Journal of Financial Economics 34, 231-250.

Hanley, K., and W.J. Wilhelm, 1995, 'Evidence on the strategic allocation of initial public offerings', Journal of Financial Economics 37, 239-257.

Harris, M., and A. Raviv, 1993, 'Differences of opinion make a horse race', Review of Financial Studies 6, 473-506.

Helwege, J., and N. Liang, 1996, 'Initial public offerings in hot and cold markets', Discussion Paper 96/34, Board of Governors of the Federal Reserve System.

Hirshleifer, D., 2001, 'Investor psychology and asset pricing', Journal of Finance 56, 1533-1597.

Houge, T., T. Loughran, G. Suchanek, and X. Yan, 2000, 'Divergence of opinion in IPOs', mimeo, University of Iowa.

Korajczyk, R.A., D.J. Lucas, and R.L. McDonald, 1991, 'The effect of information releases on the pricing and timing of equity issues', Review of Financial Studies 4, 685-708.

Krigman, L., W.H. Shaw, and K.L. Womack, 1999, 'The persistence of IPO mispricing and the predictive power of flipping', Journal of Finance 54, 1015-1044.

Lakonishok, J., A. Shleifer, and R.W. Vishny, 1994, 'Contrarian investment, extrapolation and risk', Journal of Finance 49, 1541-1578.

Lamont, O.A., and R.H. Thaler, 2000, 'Can the market add and subtract? Mispricing in tech stock carve-outs', mimeo, University of Chicago.

Lee, C.M.C., A. Shleifer, and R.H. Thaler, 1991, 'Investor sentiment and the closed-end fund puzzle', Journal of Finance 46, 75-109. 
Ljungqvist, A.P., T. Jenkinson, and W.J. Wilhelm, 2001, 'Global Integration in Primary Equity Markets: The Role of U.S. Banks and U.S. Investors', forthcoming in Review of Financial Studies.

Ljungqvist, A.P., and W.J. Wilhelm, 2001, 'IPO allocations: Discriminatory or discretionary?', forthcoming in Journal of Financial Economics.

Loughran, T., and J.R. Ritter, 1995, 'The new issues puzzle', Journal of Finance 50, $23-51$.

Loughran, T., and J.R. Ritter, 2000, 'Uniformly lest powerful tests of market efficiency', Journal of Financial Economics 55, 361-390.

Loughran, T., and J.R. Ritter, 2001, 'Why don't issuers get upset about leaving money on the table in IPOs?', forthcoming in Review of Financial Studies.

Loughran, T., J.R. Ritter, and K. Rydqvist, 1994, 'Initial public offerings: International insights', Pacific-Basin Finance Journal 2, 165-199.

Lowry, M., and G.W. Schwert, 2000, 'IPO market cycles: Bubbles or sequential learning?', mimeo, University of Rochester.

Miller, E.M., 1977, 'Risk, uncertainty, and divergence of opinion', Journal of Finance $32,1151-1168$.

Nisbett, R.E., and T.D. Wilson, 1977, 'The halo effect: Evidence for unconscious alteration of judgments', Journal of Personality and Social Psychology 35, 250-256.

Ofek, E., and M. Richardson, 2000, 'The IPO lockup period: Implications for market efficiency and downward sloping demand curve', mimeo, NYU Stern School of Business.

Myers, S.C., and N.S. Majluf, 1984, 'Corporate financing and investment decisions when firms have information that investors do not have', Journal of Financial Economics 13, 187221.

Odean, T., 1998, 'Volume, volatility, price and profit when all traders are above average', Journal of Finance 53, 1887-1934. 
Rajan, R., and H. Servaes, 1997, 'Analyst following of initial public offerings', Journal of Finance 52, 507-529.

Ritter, J.R., 1984, 'The hot issue market of 1980', Journal of Business 57, 215-240.

Ritter, J.R., 1991, 'The long-run performance of initial public offerings', Journal of Finance 46, 3-27.

Ritter, J.R., and I. Welch, 2001, Untitled, forthcoming in Journal of Finance.

Rock, K., 1986, 'Why new issues are underpriced', Journal of Financial Economics 15, $187-212$.

Shefrin, H., and M. Statman, 1995, 'Making sense of beta, size, and book-to-market', Journal of Portfolio Management 21, 323-349.

Shleifer, A., and R.W. Vishny, 'The limits of arbitrage', Journal of Finance 52, 35-55.

Welch, I., 1989, 'Seasoned offerings, imitation costs, and the underpricing of initial public offerings', Journal of Finance 44, 421-449.

Welch, I., 1992, 'Sequential sales, learning, and cascades', Journal of Finance 47, 695732. 